\title{
Kozo Kuchitsu (1927-2021): a molecular scientist
}

\author{
Istvan Hargittai ${ }^{1}$
}

Published online: 24 November 2021

(c) The Author(s), under exclusive licence to Springer Science+Business Media, LLC, part of Springer Nature 2021

\begin{abstract}
Kozo Kuchitsu (1927-2021) was a Professor of Chemistry at Tokyo University and, upon his retirement, at several other schools. He was also one of the leading electron diffraction researchers of the determination of molecular structure. He greatly contributed to the enhancement of the accuracy of structure determination. His activities had a significant impact in the international community of structural chemistry.
\end{abstract}

Keywords Gas electron diffraction $\cdot$ Molecular geometry $\cdot$ Molecular vibrations $\cdot$ Average structures $\cdot$ Accuracy in structure determination · Tokyo University

I felt the presence of Kozo Kuchitsu (1927-2021; Fig. 1) throughout my entire research career. It began in 1965 when I started building my electron diffraction laboratory in Budapest. I wrote to four international specialists in the field whose experience I thought might be useful for us. One of them was Kozo Kuchitsu. Obviously, he understood my needs and sent me four unpublished research reports about constructing his experimental apparatus. They were in Japanese, so I had them translated, and they proved to be useful indeed. I was eager to learn and this thirst for knowledge was to become a good link between us. Over the years, we met a number of times, including his visits in Budapest, and ours in Tokyo.

In spite of our numerous meetings, I did not learn much about him as a person for a long time as he was not someone to speak a great deal about himself. It was already into three decades of our interactions when he let me glimpse into his beginnings in science. In 1994, I was launching a new magazine about the culture of chemistry, The Chemical Intelligencer, and I invited Kozo to write something for its inaugural issue. He produced a beautiful paper titled "Training of a Molecular Scientist, East and West" [1]. It was mostly about the eastern aspects of his training, and this made his article especially interesting. The magazine existed for 6 years and fell victim of mergers and acquisitions of publishing

Istvan Hargittai

stuceditor@gmail.com

1 Budapest University of Technology and Economics, Budapest 1521, Hungary companies at the time. When in 2015, my son, Balazs, and I compiled a volume from the best of The Chemical Intelligencer; I made sure that Kozo's paper was there in this

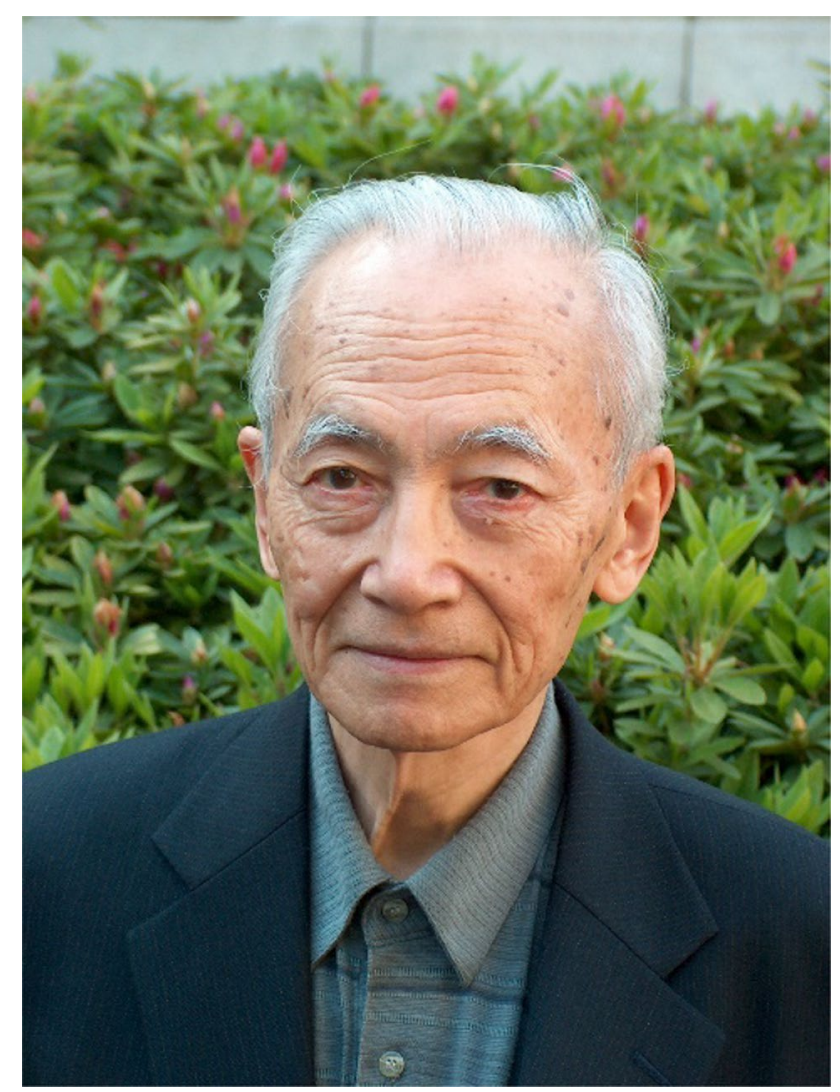

Fig. 1 Kozo Kuchitsu, 2005 in Tokyo. Photograph by I. Hargittai 
collection [2]. Re-reading his article now helped me to write about his beginnings in this brief remembrance about him.

He came from a family in the provinces. His father, being the second son, had to move to Tokyo to find work. Kozo's mother's side descended from the samurais. The family lived a simple, quiet, and polite life as it was being charted by Buddhism and Confucianism. Nobody spoke any English. When Kozo found out that one of the several possible meanings of his first name was "structure," this decided his path in science. Kozo could speak about this in a way that his audience never found out whether he was serious or just teasing. As he was not given to joking, my guess is that he meant what he told us.

From early on in his career, he wanted to learn from the best, which he first found at the University of Tokyo and later in the USA. He attended the lectures of San-ichiro Mizushima (1899-1983) at the University of Tokyo. Mizushima was a great name in molecular structures and especially in internal rotation. I used his text on conformational problems in translation from the Japanese. Mizushima guided Kozo into experimental and theoretical research of molecular structure. Kozo then joined Yonezo Morino (1908-1995), in 1950, in his gas-phase electron diffraction studies. Morino instructed his students more by example than by direct command. Kozo received altogether two instructions from him related to science. The first was that he should be studying rotational isomerism by gas electron diffraction. The second was that he should read the Journal of Chemical Physics because he will meet his future teachers and friends in its pages. Morino's reticence did not mean that he did not care for Kozo's scientific development. He worked meticulously with his pupil on his first manuscripts. When in 1969 Morino was retiring, he gave Kozo a book of Zen as a parting gift. It was about the mystical essence of civilizations. Kozo determined that the symbolic description of the book could be given in two expressions: one was "do not rely on words," and the other, "from heart to heart." It was not a simple book to digest and even after a quarter of a century; Kozo was still working on it.

Kozo found it best to describe his training by invoking the Japanese art of archery. The essence was the superiority of the spirit over the muscle in becoming a good shooter. When Kozo learned what he thought was everything he could learn in molecular science at the University of Tokyo, he left for the USA by means of a Fulbright scholarship. Originally, he intended to work for Lawrence Brockway, one of the pioneers of the gas electron diffraction technique, at the University of Michigan. When it turned out that there was no space for him, at Brockway's recommendation, he joined one of Brockway's former students, Lawrence ("Larry") S. Bartell (1923-2017). At the time, Bartell was at Iowa State University, and it proved to be the best possible venue for Kuchitsu's postdoctoral studies. In one of Bartell's papers, reminiscing about his own career, there is a photograph of
Kuchitsu posing with the Iowa State electron diffraction unit. The caption identifies Kozo Kuchitsu as a new postdoctoral scholar [3]. Bartell is most famous for his having invented electron holography. However, what Kozo was attracted by to join Larry was his pioneering work on the physical meaning of the geometrical parameters determined by experimental techniques.

Bartell was an innovative scientist whereas Morino had warned Kuchitsu early in his career that he, Kozo, would not be innovative. Rather, Morino expected Kuchitsu to become an excellent scientist for working out projects and making a superb professor. Kuchitsu, who told me about Morino's evaluation, took Morino's prophesy to heart and proved him right. His postdoctoral stint with Bartell was a success. They found a common interest in pushing the technique of electron diffraction to the limit of achievable accuracy in the determination of molecular geometry. For this, they delved deep into the intricacies of molecular vibrations, including their anharmonic components, and their impact on bond lengths. The two produced seminal papers on this topic though the high sophistication of their investigation has limited the popularity of their findings among the broader research community of molecular science. Still, if one wants to understand the meaning of accuracy in molecular structure determination, the way is to study Bartell and Kuchitsu's papers and their solo-authored papers as well. They produced accounts that have become classic describing the way of achieving the highest possible accuracy in the determination of molecular geometry. Their first targets included methane and "heavy" methane, $\mathrm{CD}_{4}$ [4], and water and heavy water [5]. Kuchitsu's role was more than a mere pupil's in these studies and he took upon himself even writing up the manuscripts. As Bartell later noted, "These studies were written up mostly by Kozo who, despite having arrived from Japan only recently, was still a much better writer of English prose than most of us Americans." [6]

Subsequently, Kuchitsu became a forceful and consistent advocate of accuracy in structure determination, which included the clear definition of basic concepts. Only someone with deep understanding of the various techniques could provide his peers with so clear a description of basic concepts as Kuchitsu did. In the Introduction to his chapter titled "Geometrical parameters of free molecules: Their definitions and determination by gas electron diffraction," he stated: "All the geometrical parameters observed by gas electron diffraction are double average values: for each individual vibrational level and then over the thermal distribution of all the vibrational (and rotational) levels." [7] As for those average values, "There are two important concepts of average internuclear distances: the average value of a distance and the distance between two average nuclear positions." ([7], p 66) These quotes demonstrate Kuchitsu's didactic prowess that characterized his lectures and writings. In 
Fig. 2 From right to left: Kozo and Sachiko Kuchitsu and Magdolna and Istvan Hargittai, 2005, Tokyo, by an unknown photographer

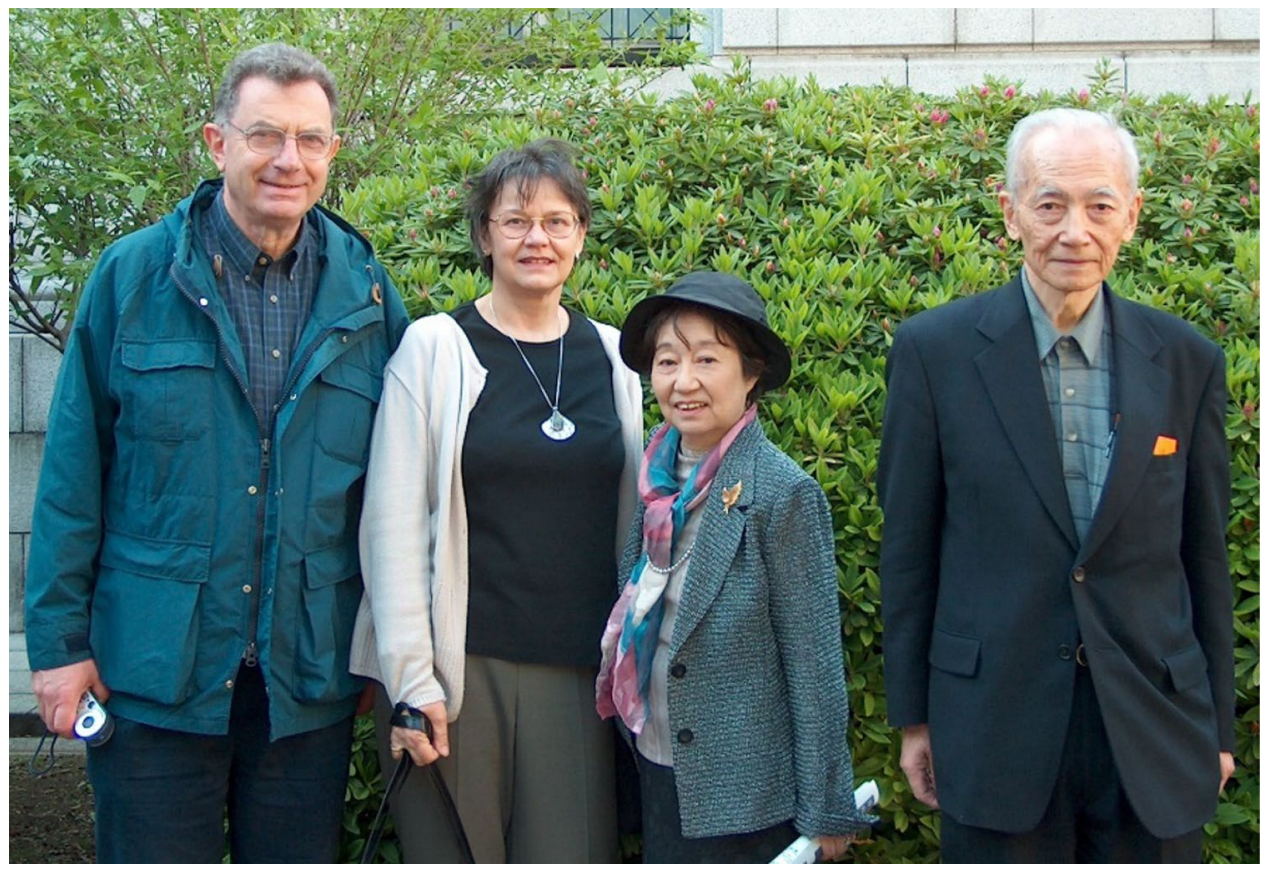

another major review, Kuchitsu elaborated on the relationship between the potential energy surface and the meaning of internuclear distances, again, focusing on the concept and requirements of accuracy [8]. His meticulous studies on the physical meaning of geometrical parameters originating from different experimental techniques greatly facilitated the combined application of experimental data from those physical techniques for a more accurate determination of molecular geometries [9].

Kozo Kuchitsu had a brilliant career in Japan and internationally through his various functions in professional organizations. This is well documented in the obituary by Kaoru Yamanouchi, one of his former pupils [10]. Here, in this highly personal remembrance, I mention only a few facts. Kuchitsu was appointed full professor in 1969, upon the retirement of his predecessor, Yonezo Morino. At the end of his career at the University of Tokyo, he served as Dean of the Faculty of Science. When he reached the compulsory retirement age at the University of Tokyo in 1988, he moved to Nagaoka University of Technology. He was professor and chair of the chemistry department until he reached the Nagaoka retirement age. His next station was Josai University. Then, his last appointment was at the Tokyo University of Agriculture and Technology. The retirement system in Japan may appear ruthless, but its stepwise arrangement among institutions of higher education makes it possible for lower-ranking schools to hire coveted professors to everybody's benefit.

Kozo Kuchitsu had a rigorous, exacting personality. He was caring and always ready to help others, but his inner warmth may have been hidden by his outer demeanor that many interpreted as rigidity. $\mathrm{He}$ and his wife, Sachiko
(Fig. 2), had two sons and one daughter. My wife and I experienced the warmth of their home. It impressed me that Kozo shared with me what his mentor had told him about his expectations of his future career. There were limits though in the depth of our long-standing interactions. I experienced what Larry Bartell complained also about, an insurmountable barrier that prevented even the slightest discussion of the experiences and lessons of World War II. Still, for me, Kozo's passing meant the loss of the person who has come closest whom I might have called a friend from his far-away culture. The community of scientists lost a great practitioner of research, an outstanding figure in international science, a relentless builder of its common language.

\section{References}

1. Kuchitsu K (1995) Training of a molecular scientist, East and West. Chem Intell 1(6):10-18

2. Kuchitsu K (2015) Training of a molecular scientist, East and West. In Hargittai B, Hargittai I (2015) Culture of chemistry: the best articles on the human side of 20th-century chemistry from the archives of the Chemical Intelligencer 107-112

3. Bartell LS (2005) Straying from the beaten path, and other stories about molecules. Struct Chem 16:17-27

4. Kuchitsu K, Bartell LS (1962a) J Chem Phys 36:2470

5. Kuchitsu K, Bartell LS (1962b) J Chem Phys 36:2460

6. Bartell LS (1999) Reminiscences about electron waves. In Hargittai M, Hargittai I, Eds. Advances in Molecular Structure Research 5:1-23 actual quote $\mathrm{p} 9$

7. Kuchitsu K (1981) Geometrical parameters of free molecules: their definitions and determination by gas electron diffraction. 
In Hargittai I, Orville-Thomas WJ, Eds, Diffraction Studies on Non-Crystalline Substances (Elsevier: Amsterdam) 63-116 actual quote $\mathrm{p} 65$

8. Kuchitsu K (1992) The potential energy surface and the meaning of internuclear distances. In: Domenicano A, Hargittai I (eds) Accurate molecular structures: their determination and importance. Oxford University Press, Oxford, pp 14-46

9. Kuchitsu K, Nakata M, Yamamoto S (1988) Joint use of electron diffraction and high-resolution spectroscopic data for accurate determination of molecular structure. In Hargittai I, Hargittai M, Eds, Stereochemical applications of gas-phase electron diffraction. Part A: the electron diffraction technique (New York: VCH Publ) pp 227-263

10. Yamanouchi K (2021) Obituary: Kozo Kuchitsu (1927-2021) Chem Phys Lett 779:138791

Publisher's Note Springer Nature remains neutral with regard to jurisdictional claims in published maps and institutional affiliations. 